Website: https://ojs.unikom.ac.id/index.php/common

DOI Jurnal: https://doi.org/10.34010/common

DOI Artikel: https://doi.org/10.34010/common.v3i2.2601

\title{
WISATA HALAL MUSLIM MILENIAL
}

\author{
Iflah $^{1}$, Kinkin Yuliaty Subarsa Putri ${ }^{2}$ \\ ${ }^{1}$ Strategic Communication, Magister Ilmu Komunikasi, Sekolah Tinggi Ilmu Komunikasi \\ (STIKOM) InterStudi \\ ${ }^{2}$ Program Studi Ilmu Komunikasi, Fakultas Ilmu Sosial, Universitas Negeri Jakarta, \\ Jl. Rawamangun Muka, Rawamangun, Pulo Gadung, Jakarta Timur, 13220, Indonesia \\ E-mail: \\ ${ }^{1}$ iflah.iflah@gmail.com \\ 2 kinkinsubarsa@unj.ac.id
}

\begin{abstract}
Year to year halal tourism is starting to become popular, in line with the increase in Muslim tourists. Development of halal tourism now carried out by various countries, both majority Muslim and non-Muslim countries. Target of halal tourism market is growing rapidly in the millennial Muslim because it is considered potential in driving halal tourism development. This study of halal tourism seeks to interpret cultural tourism which is synergized with the halal industry as a spiritual experience of modern society, namely millennial Muslims. This literature review will disscuss millennial Muslims in Indonesia as the main segment in utilizing the potential offered from domestic and foreign halal tourism based on literature and other references relating to halal tourism and Y generations. This literature study aims to explore halal tourism at local and abroad which focuses on the segmentation of millennial Muslims as a population that is considered potential in increasing halal tourism development. Focus on study in a particular segmentation is expected to be able to broaden the understanding of the concept of halal tourism from the perspective of the younger generation so that the halal tourism industry is able to develop according to the changes and needs of the times.
\end{abstract}

Keywords: Halal Tourism, Millennials, Muslims

\begin{abstract}
Abstrak
Wisata halal saat ini menjadi mulai banyak diminati, hal tersebut seiring dengan peningkatan wisatawan muslim dari tahun ke tahun. Pengembangan wisata halal kini banyak dilakukan oleh berbagai negara, baik negara mayoritas muslim maupun non-muslim. Target pasar wisata halal tumbuh pesat pada segmen muslim milenial karena dianggap potensial dalam menggerakkan perkembangan wisata halal. Studi tentang wisata halal ini berupaya memaknai pariwisata budaya yang disinergiskan dengan industri halal sebagai pengalaman spiritual masyarakat modern yaitu muslim milenial. Kajian literatur ini akan membahas tentang muslim milenial di Indonesia sebagai segmen yang utama dalam memanfaatkan potensi yang ditawarkan dari wisata halal dalam negeri maupun luar negeri berdasarkan literatur dan referensi lainnya yang berkaitan dengan wisata halal dan muslim generasi Y. Studi literatur ini bertujuan untuk mengeksplorasi wisata halal dalam dan luar negeri yang berfokus pada segmentasi muslim milenial sebagai populasi yang dianggap potensial dalam meningkatkan perkembangan wisata halal. Memiliki fokus studi dalam sebuah segmentasi tertentu diharapkan mampu memperluas pemahaman akan konsep wisata halal dari sudut pandang generasi muda agar industri pariwisata halal mampu berkembang menyesuaikan dengan perubahan dan kebutuhan zaman.
\end{abstract}

Kata Kunci: Wisata Halal, Milenial, Muslim 
Website: https://ojs.unikom.ac.id/index.php/common

DOI Jurnal: https://doi.org/10.34010/common

DOI Artikel: https://doi.org/10.34010/common.v3i2.2601

\section{Pendahuluan}

\subsection{Latar Belakang}

Tahun 1996 merupakan era dimana industri komunikasi berubah menjadi sebuah kebutuhan yang membentuk nilai ekonomi lebih luas serta keberadaannya tidak dapat dihindari (Jürgen Albinger, 2009).

Perkembangan komunikasi yang pesat menyebabkan rasa dari masyarakat menjadi sulit dibendung karena akses dan segala kemudahan untuk berpergian atau menuju ke suatu tempat tidak lagi menjadi kendala. Kini semua daerah maupun negara membuka diri dan menyebut negara lain sebagai tamu yang tidak patut dicurigai.

Keterbukaan akses dunia dalam informasi dan komunikasi menjadi faktor penting sebagai pendorong promosi sektor pariwisata karena mayoritas disebabkan kemudahan wadah dalam mengembangkan informasi dan komunikasi sehingga masyarakat memiliki gambaran, harapan dan imajinasi berdasarkan berita dan koneksi yang telah tersebar luas. Saat ini produk dan bentuk pengiklanan industri pariwisata juga semakin menarik dan beragam, seperti dikemas dalam wisata budaya, wisata ilmiah, wisata edukasi, wisata lingkungan, wisata religi, dan lain sebagainya (Mansour Esmaeil Zaei \& Mahin Esmaeil Zaei, 2013).

Wisata religi dan motivasi kerohanian kini telah menjamur dan menjadi daya tarik baru dalam beberapa tahun terakhir, bahkan popularitas budaya dan praktek keagamaan menjadi sorotan wisatawan untuk mengunjungi negara yang identik dengan budaya religi. Menurut sebuah artikel, sebutan wisata religi kini semakin berkembang diiringi dengan perkembangan ekonomi syariah secara global, lalu berubah dengan istilah wisata syariah, bahkan dalam beberapa tahun terakhir kembali terjadi perubahan istilah yang sering disebut wisata halal (Jaelani, 2017).

Dalam artikel yang berjudul "Halal Tourism Industry in Indonesia: Potential and Prospect" menunjukkan bahwa negara seperti Indonesia dengan mayoritas warga muslim mampu mengembangkan wisata halal yang dapat menjadi contoh wisata halal dunia (Jaelani, 2017). Penelitian dengan judul "Upaya Indonesia Meningkatkan Daya Saing Muslim Friendly Tourism (MFT) di antara Negara-Negara OKI" menunjukkan adanya komitmen membangun wisata ramah terhadap muslim dengan mendistribusikan anggaran secara proporsional dalam membangun wisata halal dengan melakukan beberapa standarisasi berdasarkan kesepakatan serta memperkenalkan konsep wisata halal dari dan/oleh negara-negara anggota Organisasi Kerjasama Islam (OKI) (Komalasari, 2017). Dalam penelitian yang berjudul "Diplomasi Pariwisata Halal Nusa Tenggara Barat" menjelaskan bahwa pariwisata halal berperan penting dalam hal diplomasi publik untuk meningkatkan jumlah wisatawan di Nusa Tenggara Barat (Subarkah, 2018). Ketiga penelitian tersebut menunjukkan adanya peluang positif bagi negara maupun daerah yang ingin mengembangkan sektor wisata halal yang potensial sebagai industri pariwisata berdasarkan prinsip keislaman (syariah).

Tren tentang wisata halal kini mengemuka dan mulai banyak diminati masyarakat, seiring dengan peningkatan pengetahuan dan informasi tentang pertumbuhan industri halal karena adanya ekalasi jumlah wisatawan muslim merupakan peluang dalam sektor pariwisata (Abdul Rahman, Rezai, Mohamed, Shamsudin, \& Sharifuddin, 2013).

Wisata halal adalah kegiatan yang didukung dengan berbagai fasilitas serta layanan yang disediakan oleh pemerintah, pengusaha bahkan masyarakat yang mampu 
Website: https://ojs.unikom.ac.id/index.php/common

DOI Jurnal: https://doi.org/10.34010/common

DOI Artikel: https://doi.org/10.34010/common.v3i2.2601

memenuhi ketentuan syariah (Kementerian Pariwisata, 2012). Wisata halal bertujuan memberikan pelayanan terhadap wisatawan yang menginginkan perjalanan sesuai dengan kaidah-kaidah keislaman, sehingga wisatawan (terutama muslim) merasa lebih nyaman dan aman dalam berwisata, serta dapat menjalankan kewajibannya sebagai muslim seperti halnya kewajiban mengonsumsi makanan dan minuman halal, menjalankan sholat wajib di tempat yang sesuai dan mendapatkan penginapan yang representatif (Subarkah, 2018).

Meningkatnya sektor industri tersebut mempengaruhi munculnya wisata halal sebagai sebuah fenomena yang menarik (Samori, Md Salleh, \& Khalid, 2016). Menurut beberapa literatur dijelaskan bahwa saat ini wisatawan muslim lebih peduli terhadap konsumsi produk bahkan layanan agar tetap dapat mengikuti prinsipprinsip syariah saat berpergian (Battour, 2018; Battour \& Ismail, 2016; Battour, Ismail, \& Battor, 2011; Jafari \& Scott, 2014).

Industri pariwisata halal tersebut dianggap memiliki peluang dan potensi yang besar sehingga banyak negara berbondong-bondong mulai memberikan pelayanan produk, fasilitas, layanan serta infrastruktur pariwisata pendukung wisata halal agar mampu memenuhi kebutuhan wisatawan muslim. Meskipun demikian, banyak pihak di sektor lain maupun sektor yang sama (pariwisata) masih memiliki kendala dalam memahami konsep wisata halal tersebut (El-Gohary, 2016; Han, AlAnsi, Olya, \& Kim, 2019; Mohsin, Ramli, \& Alkhulayfi, 2016).

Jika dikaji lebih mendalam terdapat beberapa segmentasi yang dapat mengalami peningkatan pesat dalam perkembangan industri pariwisata halal, beberapa di antaranya yaitu: (1) meningkatnya pertumbuhan populasi muslim, (2) meningkatnya pertumbuhan middle class income dari populasi muslim, (3) meningkatnya akses informasi dari berbagai media sehingga dengan cepat dan mudah diketahui oleh masyarakat, (4) populasi muslim dengan usia rata-rata 24 tahun di tahun 2015 menjadi peluang karena pada usia muda tersebut sering melakukan perjalanan wisata (travelling), (5) meningkatnya fasilitas dan pelayanan yang ramah terhadap wisatawan muslim, (6) adanya Ramadhan Travel menjadikan wisatawan muslim tertarik berkunjung pada bulan Ramadhan, dan (7) bisnis travel yang semakin menjamur dan cepat menangkap peluang dalam pelayanan wisatawan muslim (Global Muslim Travel Index, 2018).

Berdasarkan beberapa segmentasi yang tersebut di atas, terdapat poin yang dapat digarisbawahi yaitu jumlah populasi muslim dan jumlah populasi muslim dengan usia muda. Target pasar wisata halal tumbuh pesat pada segmen muslim milenial karena dalam hal populasi berdasarkan usia rata-rata muslim pada tahun 2010 berada di usia 23 tahun. Wisatawan muslim milenial ini sering disebut sebagai Generasi Y yang berada dalam rentang usia 20 tahun hingga 38 tahun merupakan segmen yang potensial dalam menggerakkan pertumbuhan pasar wisata halal dan merupakan konsumen dengan pertumbuhan paling cepat yang mewakili hampir $20 \%$ wisatawan internasional. Prediksi pada tahun 2020, generasi muslim milenial diharapkan mencapai 320 juta perjalanan internasional setiap tahunnya, yang dapat menjadi representatif kenaikan $47 \%$ dari 217 juta di tahun 2013. Muslim milenial, dalam satu tahun mampu menghabiskan waktu berlibur dua kali hingga lima kali berpergian wisata (Mastercard \& Halal Trip, 2017).

Kajian literatur ini akan membahas tentang muslim milenial di Indonesia sebagai segmen yang utama dalam 
Website: $\underline{\text { https://ojs.unikom.ac.id/index.php/common }}$

DOI Jurnal: https://doi.org/10.34010/common

DOI Artikel: https://doi.org/10.34010/common.v3i2.2601

memanfaatkan potensi yang ditawarkan dari wisata halal dalam negeri maupun luar negeri berdasarkan literatur dan referensi lainnya yang berkaitan dengan wisata halal dan muslim generasi Y (milenial).

\subsection{Maksud dan Tujuan}

Studi literatur ini bertujuan untuk mengeksplorasi wisata halal dalam dan luar negeri yang berfokus pada segmentasi muslim milenial sebagai populasi yang dianggap potensial dalam meningkatkan perkembangan wisata halal. Beberapa literatur terdahulu banyak membahas konsep wisata halal dalam konteks ekonomi, globalisasi dan bisnis. Memiliki fokus studi dalam sebuah segmentasi tertentu diharapkan mampu memperluas pemahaman akan konsep wisata halal dari sudut pandang generasi muda agar industri pariwisata halal mampu berkembang menyesuaikan dengan perubahan dan kebutuhan zaman.

Kajian studi ini bermaksud sebagai bahan referensi dan literatur penulisan selanjutnya serta diharapkan mampu memberikan pencerahan bagi generasi muslim milenial untuk memberikan kontribusi terhadap industri wisata halal menjadi sektor unggulan di Indonesia.

Studi tentang wisata halal ini berupaya memaknai pariwisata budaya yang disinergiskan dengan industri halal sebagai pengalaman spiritual masyarakat modern yaitu muslim milenial.

\section{Kajian Pustaka dan Kerangka Pemikiran}

\subsection{Wisata Halal}

Populasi muslim saat ini mencapai sekitar $30 \%$ dari total populasi di dunia (Kim, Im, \& King, 2015). Jumlah ini diperkirakan akan terus meningkat. Peningkatan ini diperhitungkan lebih tinggi dibandingkan populasi agama lainnya (Pew
Research Center, 2017) dan diperkirakan populasi muslim antara tahun 2015 hingga 2060 akan meningkat menjadi 70\%, sedangkan populasi dunia meningkat sebesar $32 \%$ atau jumlah total populasi dunia pada tahun 2060 sebanyak 9,6 miliar orang. Hal ini dapat mengisyaratkan bahwa wisatawan muslim dapat ikut meningkat. Pada tahun 2020 wisatawan muslim diperkirakan akan meningkat menjadi 30\% dan mampu meningkatkan nilai pengeluaran hingga 200 miliar USD (Mastercard dan Crescent Rating, 2016).

Pariwisata muncul sebagai wujud kebutuhan setiap orang dan interaksi antar wisatawan dan masyarakat setempat, bahkan Pemerintah, Pemerintah Daerah dan pengusaha. Wisata atas dasar tujuan ke tempat bersejarah atau tujuan spiritual (agama) untuk wisatawan internasional dapat memberikan pendapatan tambahan ke negera muslim. Selain itu, Organisasi Konferensi Islam (OKI) telah menyatakan untuk mengembangkan kegiatan wisata bagi negara-negara anggota OKI, karena semakin banyak wisatawan muslim dalam dunia Islam dapat menambah pemahaman yang lebih baik, mengundang sebuah kolaborasi dalam melayani kepentingan umum (Jaelani, 2017). World Tourism Organization (WTO) menganjurkan konsumsi wisata halal bukan hanya diperuntukkan bagi umat muslim namun juga bagi non-muslim yang ingin menikmati kearifan lokal. Adapun kriteria umum dari wisata halal adalah: (1) memiliki orientasi pencerahan, penyegaran dan ketenangan, (2) memiliki orientasi kepada manfaat umum, (3) menghindari dari hal-hal yang disenangi oleh Allah, (4) menjaga adab dan kenyamanan (5) bebas dari maksiat, (6) menjaga kelestarian lingkungan serta, (7) menghormati nilainilai sosial budaya dan kearifan lokal.

Adanya peningkatan dalam jumlah wisatawan muslim merupakan peluang 
Website: https://ojs.unikom.ac.id/index.php/common

DOI Jurnal: https://doi.org/10.34010/common

DOI Artikel: https://doi.org/10.34010/common.v3i2.2601

untuk mengembangkan wisata halal sehingga beberapa negara mulai mengambil kesempatan dalam mengembangkan wisata halal, baik negara dengan mayoritas muslim maupun non-muslim seperti Australia, Korea Selatan, Thailand dan Jepang. Bagi hotel, restoran, tempat-tempat wisata, maskapai penerbangan, agen travel/perjalanan serta semua yang ikut serta dalam industri pariwisata juga dapat terlibat dalam wisata halal (Battour \& Ismail, 2016).

\section{Gambar 1. Proyeksi Pertumbuhan Penduduk berdasarkan Agama}

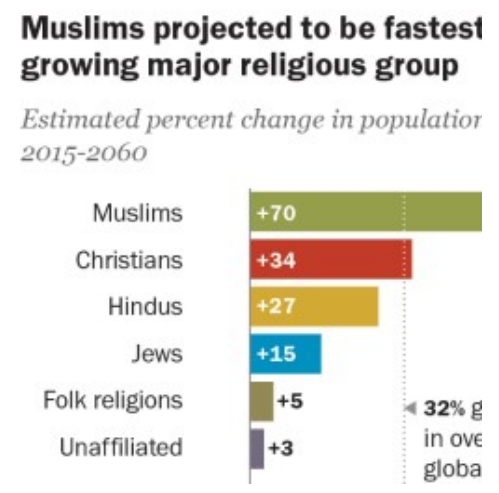

Sumber : Pew Research Center, 2017

Wisata halal kini menjadi tren dalam industri pariwisata dunia, bahkan dalam kemajuannya, wisata halal signifikan dalam peningkatan. Sejak tahun 2014 terdapat 108 juta wisatawan muslim yang melakukan perjalanan wisata, lalu meningkat di tahun 2015 mencapai 117 juta wisatawan muslim, pada tahun 2016 mencapai 121 juta dan mengalami peningkatan pula pada tahun 2017 mencapai 131 juta wisatawan muslim. Total nilai perjalanan wisatawan muslim secara global diprediksi mengalami peningkatan dari tahun 2014 mencapai nilai USD 145 miliar dan jika mencapai pada tahun 2026 mampu menghasilkan USD 300 miliar (Global Muslim Travel Index, 2018).

Adanya peningkatan wisatawan muslim dari tahun ke tahun menjadi peluang namun juga sebuah tantangan pula bagi sektor pariwisata dalam mengembangkan wisata halal. Kini banyak negara baik mayoritas muslim maupun non-muslim berupaya mengembangkan wisata halal dengan menawarkan konsep dan prinsip, negara-negara tersebut umumnya mencoba menciptakan suasana yang ramah muslim.

Berdasarkan literatur yang membahas pariwisata halal, terdapat berbagai istilah yang digunakan seperti wisata islami (islamic tourism) atau wisata halal (halal tourism) (Al-Hamarneh, 2005; El-Gohary, 2016; Henderson, 2010; Razalli, Abdullah, \& Hassan, 2012). Berikut adalah definisi wisata islami menurut beberapa sumber.

Tabel 1. Definisi Wisata Islami (Islamic Tourism)

\begin{tabular}{|c|c|}
\hline Sumber & Definisi \\
\hline $\begin{array}{c}\text { Islamic Tourism } \\
\text { Centre-Malaysia } \\
(2015)\end{array}$ & $\begin{array}{c}\text { Setiap aktivitas, peristiwa dan } \\
\text { pengalaman yang dilakukan } \\
\text { dalam sebuah perjalanan wisata } \\
\text { yang sesuai dengan konsep } \\
\text { islami. }\end{array}$ \\
\hline $\begin{array}{c}\text { Al-Hamarneh } \\
(2011)\end{array}$ & $\begin{array}{c}\text { Sebuah konsep ekonomi, } \\
\text { budaya dan religius dalam } \\
\text { konteks konservatif. }\end{array}$ \\
Henderson (2011) & $\begin{array}{c}\text { Semua pengembangan produk } \\
\text { dan upaya pemasaran yang } \\
\text { dirancang untuk umat Islam. }\end{array}$ \\
\hline
\end{tabular}

Sumber: Satriana \& Faridah, 2018

Berdasarkan tabel 1, wisata islami lebih berfokus pada isu-isu yang berbeda seperti: partisipasi dan keterlibatan muslim, dimensi sosial, ekonomi, budaya, agama dan lain sebagainya, serta pengelolaan layanan seperti pemasaran, pertimbangan budaya dan agama.

Dalam konteks pariwisata halal didefinisikan sebagai salah satu konsep yang muncul terkait dengan kehalalan dan telah didefiniskan dalam berbagai cara oleh beberapa ahli. Sebagian definisi wisata 
Website: https://ojs.unikom.ac.id/index.php/common

DOI Jurnal: https://doi.org/10.34010/common

DOI Artikel: https://doi.org/10.34010/common.v3i2.2601

halal (halal tourism) dijelaskan dalam tabel berikut.

Tabel 2. Definisi Wisata Halal (Halal Tourism)

\begin{tabular}{|c|c|}
\hline Sumber & Definisi \\
\hline Battour dan & Kegiatan dalam pariwisata yang \\
Ismail (2016) & diizinkan atau diperbolehkan \\
& menurut ajaran Islam. \\
\hline & Penyediaan produk dan layanan \\
Mohsin, dkk & pariwisata yang mampu \\
(2016) & memenuhi kebutuhan \\
& wisatawan muslim sesuai \\
& dengan ajaran agama Islam. \\
\hline
\end{tabular}

Sumber: Satriana \& Faridah, 2018

Berdasarkan kedua tabel definisi, dijelaskan bahwa definisi wisata halal (halal tourism) dan wisata islami (islami tourism) menunjukkan definisi yang hampir sama yaitu dimana terdapat adanya pernyataan "sesuai ajaran Islam".

Indonesia merupakan negara yang memiliki penduduk mayoritas beragama Islam (BPS, 2010). Potensi ini dimanfaatkan untuk terus berupaya memaksimalkan wisata halal, didukung dengan letak geografis yang strategis. Selain itu, iklim tropis Indonesia menjadi potensial sebagai negara tujuan wisatawan. Produk wisata yang ditawarkan juga cukup beragam (Gilang Widagdyo, 2015).

Di negara dengan mayoritas muslim maupun non-muslim, dalam ketersediaan restoran halal maupun hotel syariah masih terbatas. Keterbatasan tersebut dipengaruhi oleh kurangnya pemahaman terkait kehalalan (El-Gohary, 2016; Han et al., 2019; Mohsin et al., 2016). Oleh karena itu, pendidikan maupun riset berkaitan wisata halal sangat diperlukan. Selain itu, diperlukan pula standarisasi dalam wisata halal yakni sertifikasi halal di restoran, hotel dan lain sebagainya.

Berbagai upaya telah dilakukan untuk mengembangkan wisata halal di Indonesia, seperti meningkatkan jumlah hotel syariah dimana hotel-hotel tersebut menjalanan prinsip-prinsip Islam sebagaimana yang telah diatur dalam bentuk fatwa dan disetujui oleh Majelis Ulama Indonesia (MUI). Sejak tahun 2013, terdapat 37 hotel syariah yang memiliki sertifikasi dan 150 hotel sedang dalam proses operasionalisasi menuju sertifikasi syariah dan akan terus berkembang (Kementerian Pariwisata, 2015).

Dalam hal makanan dan minuman, dilakukan sertifikasi halal oleh MUI yang ditandai dengan logo halal resmi pada kemasan atau label restoran dan akan dilakukan pemeriksaan rutin oleh Badan Pengawas Obat dan Makanan (BPOM) sehingga makanan dan minuman yang tersedia tetap terjamin kualitas serta kehalalannya bagi setiap warga termasuk wisatawan. Untuk warga dan wisatawan non-muslim dapat mempercayai bahwa label tersebut menunjukkan tidak adanya kandungan zat berbahaya bagi tubuh sehingg aman untuk dikonsumsi (Jaelani, 2017). Terdapat sebanyak 2.916 restoran dan 303 diantaranya telah memiliki sertifikasi halal dan 1.800 lainnya sedang dipersiapkan menuju sertifikasi halal (Kementerian Pariwisata, 2015). Berikut adalah kriteria umum dalam mengembangakan wisata halal berdasarkan badan dibawah pengelolaan Kementerian Pariwisata Republik Indonesia yang berwenang dan bertanggung jawab dalam mengatur pariwisata Indonesia. 
Website: https://ojs.unikom.ac.id/index.php/common

DOI Jurnal: https://doi.org/10.34010/common

DOI Artikel: https://doi.org/10.34010/common.v3i2.2601

Tabel 3. Kriteria Umum Wisata Halal (Halal Tourism)

\begin{tabular}{|c|c|}
\hline Kategori & Indikator \\
\hline \multirow{4}{*}{$\begin{array}{l}\text { Destinasi Wisata } \\
\text { (Alam, Budaya, } \\
\text { Buatan) }\end{array}$} & $\begin{array}{l}\text { Tersedia pilihan aktivitas wisata, seni dan budaya yang } \\
\text { tidak mengarah pada pornoaksi dan kemusyrikan }\end{array}$ \\
\hline & $\begin{array}{l}\text { Jika memungkinkan menyelenggarakan minimal satu } \\
\text { festival Halal Lifestyle }\end{array}$ \\
\hline & Pramuwisata berpakaian dan berpenampilan sopan \\
\hline & $\begin{array}{l}\text { Tersedia pilihan daya tarik wisata pantai dan pemandian } \\
\text { yang terpisah untuk pria dan wanita dan/atau } \\
\text { mempunyai aturan pengunjung tidak berpakaian minim }\end{array}$ \\
\hline \multirow{6}{*}{ Hotel } & Tersedia makanan halal \\
\hline & $\begin{array}{l}\text { Tersedia fasilitas yang memudahkan untuk beribadah, } \\
\text { seperti: Mesjid, Musholla dan fasilitas bersuci }\end{array}$ \\
\hline & $\begin{array}{l}\text { Tersedia pelayanan saat bulan Ramadhan untuk } \\
\text { memenuhi kebutuhan sahur dan berbuka puasa }\end{array}$ \\
\hline & $\begin{array}{l}\text { Tidak adanya aktivitas non-halal seperti perjudian, } \\
\text { minuman beralkohol dan kegiatan diskotik }\end{array}$ \\
\hline & $\begin{array}{l}\text { Tersedia fasilitas kolam renang dan fasilitas } \\
\text { kebugaran/gym yang terpisah antara pria dan wanita }\end{array}$ \\
\hline & $\begin{array}{l}\text { Jika hotel menyediakan fasilitas spa, maka terapis pria } \\
\text { untuk pelanggan pria dan terapis wanita untuk } \\
\text { pelanggan wanita. Terapi tidak boleh menggunakan } \\
\text { bahan mengandung babi, alkohol maupun produk } \\
\text { turunannya }\end{array}$ \\
\hline \multirow{5}{*}{ Biro Perjalanan } & $\begin{array}{l}\text { Menyediakan paket wisata yang sesuai dengan kriteria } \\
\text { umum Wisata Halal Kementerian Pariwisata RI }\end{array}$ \\
\hline & Tidak menawarkan aktivitas non-halal \\
\hline & Memiliki daftar penyedia dan minuman halal \\
\hline & $\begin{array}{l}\text { Pemandu wisata memahami dan mampu melaksanakan } \\
\text { nilai-nilai syariah dalam menjalankan tugas }\end{array}$ \\
\hline & $\begin{array}{l}\text { Berpenampilan sopan dan menarik sesuai dengan etika } \\
\text { Islam }\end{array}$ \\
\hline
\end{tabular}

Sumber: Tim Percepatan Pembangunan Pariwisata Halal (Garit Bira Widhasti, 2018)

\subsection{Muslim Milenial}

Ahli sejarah maupun ahli budaya membagi tahapan waktu dalam beberapa periode atau generasi. Adanya tahap periode generasi ini dapat mempermudah proses identifikasi permasalahan, karakter, maupun tren di setiap generasinya. Berikut adalah "generation timeframe" yang telah disusun berdasarkan artikel yang berjudul "Peran Generasi Milenia Muslim dalam Pengembangan Ekonomi Kreatif Berbasis Kearifan Lokal".
Gambar 2. Generation Timeframe

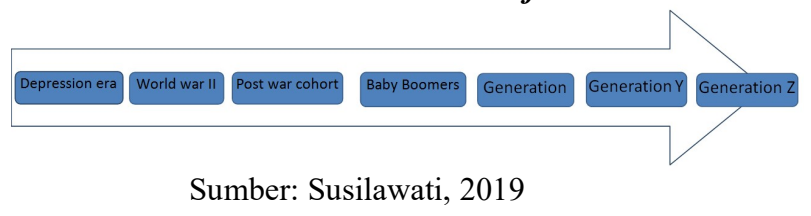

Adanya pengaruh besar globalisasi terhadap kehidupan khususnya bangsa Indonesia, baik pengaruh positif maupun negatif di era saat ini maka perlu adanya kemampuan masyarakat yang baik dalam mencegah dan mengurangi pengaruh negatif tersebut khususnya pada generasi milenial. Dari usia mereka sangat muda dan kedepan mereka akan memegang peran yang sangat penting dalam kurun waktu 10 tahun ke depan. Sesuai dengan data BPS terdapat $50 \%$ penduduk dengan usia produktif dan berasal dari generasi milenial dan akan mencapai angka $70 \%$ dari penduduk usia produktif pada tahun 2020 sampai dengan tahun 2030. Generasi ini memiliki ciri dan karakter yang khas dan berbeda dibanding dengan generasi sebelumnya. Dijelaskan pula generasi milenial sering disebut memiliki ciri menyukai kebebasan, senang melakukan personalisasi, mengandalkan kecepatan informasi yang instan, suka belajar dan bekerja dengan lingkungan inovatif, aktif berkolaborasi dan hypertechnology (Nugraheni \& Nugraha, et.al, 2019). Dalam perspektif Absher dan Amidjaya dijelaskan bahwa generasi milenial berkisar antara 1982 sampai 2002 dan mengalami google generation, net generation, generation $Z$, echo boomers, dan dumbest generation (Nugraheni \& Nugraha, et.al, 2019).

Fakta tersebut menyebabkan dewasa ini Indonesia dihadapkan pada keberadaan generasi milenial. Milenial adalah generasi pertama yang menyandang digital native, yang berarti bahwa penggunaan teknologi merupakan hal terpenting pada era ini, seperti perilaku generasi milenial di Indonesia saat ini yang sangat candu pada 
Website: https://ojs.unikom.ac.id/index.php/common

DOI Jurnal: https://doi.org/10.34010/common

DOI Artikel: https://doi.org/10.34010/common.v3i2.2601

internet. Hal yang bisa dilakukan cukup beragam dan terkait apa saja yang dapat memberi peluang penerapan halal lifestyle platform, seperti liburan kapan saja, dimana saja, kerja cepat dan kerja cerdas.

Berikut ini merupakan beberapa data jumlah banyaknya milenial Indonesia dan negara lain yang menjadi potensi bagi penerapan halal lifestyle. Dapat dilihat berdasarkan data di bawah, Indonesia menempati peringkat satu dalam hal jumlah interaksi milenial di bidang halal lifestyle (Agustina \& Afriadi, et.al, 2019).

\section{Tabel 4. Volume Transaksi Milenial per-Negara dan Sektor}

\begin{tabular}{|c|c|c|c|c|c|c|c|}
\hline Negara & $\begin{array}{c}\text { Islamic } \\
\text { Finance }\end{array}$ & $\begin{array}{c}\text { Halal } \\
\text { Food }\end{array}$ & $\begin{array}{c}\text { Modest } \\
\text { Fashion }\end{array}$ & $\begin{array}{c}\text { Halal } \\
\text { Travel }\end{array}$ & $\begin{array}{c}\text { Halal } \\
\text { Media }\end{array}$ & $\begin{array}{c}\text { Halal } \\
\text { Cosmetics }\end{array}$ & Total \\
\hline Indonesia & 37.500 & 4.200 & 68.500 & 4.600 & 4.200 & 7.800 & $\mathbf{1 2 8 . 8 0 0}$ \\
\hline Malaysia & 60.600 & 7.400 & 5.300 & 1900 & 1.400 & 8.100 & $\mathbf{8 4 . 7 0 0}$ \\
\hline Pakistan & 4.000 & 1.200 & 1.500 & 500 & 48.500 & 200 & $\mathbf{5 5 . 9 0 0}$ \\
\hline USA & 2.500 & 6.800 & 1.100 & 1500 & 2.200 & 500 & $\mathbf{1 4 . 6 0 0}$ \\
\hline Filipina & 400 & 7.700 & 1.200 & 100 & 200 & 4.300 & $\mathbf{1 3 . 9 0 0}$ \\
\hline India & 1.800 & 2.500 & 500 & 300 & 5.200 & - & $\mathbf{1 0 . 3 0 0}$ \\
\hline UK & 600 & 2.700 & 400 & 300 & 1.000 & 100 & $\mathbf{5 . 1 0 0}$ \\
\hline Turkey & - & - & - & - & 4.900 & - & $\mathbf{4 . 9 0 0}$ \\
\hline UAE & 300 & 300 & 200 & - & 3.000 & - & $\mathbf{3 . 8 0 0}$ \\
\hline
\end{tabular}

Pariwisata Indonesia tidak bisa terlepas dengan generasi milenial atau posisi mereka sebagai sosok "influencer promotion" yang lebih memilih untuk melakukan wisata dengan bentuk petualangan dan biaya yang hemat, inilah yang sedang dilakukan Pemerintah demi mengakomodasi wisatawan generasi milenial yang di tahun 2019 mencapai tujuh juta dari total target wisatawan. Pada tahun 2018 Indonesia menduduki peringkat 9 sebagai Negara dengan pertumbuhan pariwisata tertinggi di dunia oleh The World Travel and Tourism Council (WTTC) (Wulandari \& Ohorella, 2019).
Kementerian Pariwisata dalam hal ini membidik milenial bukan tampah sebab, pernyataan Kementerian Pariwisata yang mengatakan bahwa target pertumbuhan wisatawan milenial dapat menjadikan milenial sebagai "powering influencer" dan tanpa disadari wisatawan milenial memiliki kecapakan dalam hal advokasi dan mampu menceritakan kembali sesuai kreatifitas dengan petualangan yang didapatkan. Generasi milenial, memang telah dipersiapkan oleh Kementerian Pariwisata dalam mendukung keberhasilan destinasi wisata yang ada, dengan membentuk sebuah komunitas Pariwisata yang dikenal dengan Generasi Pesona Indonesia (GENPI). Komunitas ini diharapkan menjadi garda terdepan yang memperkenalkan pariwisata baik nasional maupun internasional, dengan menjadikan anggotanya sebagai "digital influencer". Adapun kegiatan yang sering dilaksanakan adalah menjadi endorser pariwisata dan mengajak followers untuk ikut andil menikmati dan mempromosikan pariwisata. Komunitas ini dijadikan gerbang untuk menarik milenial lainnya untuk menjadi "influencer tourism" yang mempunyai aspek Creative Value dan Commercial Value. Antusiasme generasi milenial secara serius oleh Pemerintah atau pelaku usaha, salah satunya Pariwisata 4.0 yang berkaitan dengan social media yang digunakan oleh milenial dalam melakukan perjalanan (Wulandari \& Ohorella, 2019)

Generasi milenial dihadapkan pada kenyataan bahwa pariwisata menjadi komoditas utama dalam hidup yang wajib dilaksanakan, apalagi dengan aktifitas yang begitu banyak memberikan momen momen seru untuk diabadikan dalam perangkat elektronik dan (Utama \& Mahadewi, 2018).

Wisatawan milenial pada umumnya merupakan kelompok yang unik dengan karakter, kebutuhan, harapan dan motif 
Website: $\underline{\text { https://ojs.unikom.ac.id/index.php/common }}$

DOI Jurnal: https://doi.org/10.34010/common

DOI Artikel: https://doi.org/10.34010/common.v3i2.2601

khusus. Generasi milenial adalah penduduk asli digitalisasi dan informasi, segmen pasar ini sering memberikan banyak waktu dan usaha dalam melaksanakan riset secara menyeluruh sebelum melakukan wisata.

Dikenal sebagai konsep 3A, pada generasi milenial dalam memengaruhi keputusan mereka sebelum melakukan perjalanan, yaitu:

a) Accessible: Technology, Information, Sharing.

b) Authentic: Destination discovery, Local Cuisine, Flexible itinerary;

c) Affordable: Accommodation, Transport, Experiences;

Konsep 3A ini dapat merangkum pola perjalanan utama dalam seluruh pengalaman perjalanan wisatawan muslim milenial mulai dari perencanaan hingga berbagi pengalamannya dengan orang lain, terutama dikarenakan internet dan lingkungan sosial saat ini berperan penting dalam kehidupan sehari-hari, tujuan dan penyedia layanan pariwisata minimal harus mampu mengembangkan penawaran yang sesuai dengan konsep 3A agar mampu memfasilitasi generasi muslim milenial dalam segmen wisata halal ini (Mastercard \& HalalTrip, 2017). Segmen pasar generasi milenial sangat menghargai wisata sebagai sebuah gaya hidup dan pengalaman hidup bahkan wisata untuk berbagai alasan.

Melakukan perjalanan wisata menjadi lebih dari sekedar liburan bagi generasi milenial, wisata menjadi sering dilakukan untuk pertumbuhan dan perkembangan pribadi, dalam mencari pengalaman baru bahkan untuk menjalin ikatan sosial karena dapat memberikan kesempatan untuk bertemu dengan orang-orang baru yang memiliki ikatan sosial dan budaya yang berbeda (Mastercard \& HalalTrip, 2017).

Dalam melakukan perjalanan wisata, segmen generasi muslim milenial ini memperhatikan pengeluaran biaya perjalanan. Biaya yang dikeluarkan sekitar
1,5 juta rupiah hingga 7 juta rupiah, biaya ini tergolong kecil karena wisatawan muslim milenial ini sebagaian besar terdiri anak-anak sekolah atau mahasiswa, anakanak yang baru lulus sekolah atau kuliah, karyawan-karyawan baru yang memiliki biaya terbatas sehingga biaya menjadi penting dalam merencanakan kegiatan wisata. Generasi muslim milenial ini dapat menghabiskan setidaknya untuk 5 (lima) hal yaitu: (1) penerbangan, (2) akomodasi, (3) makanan, (4) belanja dan, (5) aneka barang-misalnya tiket masuk, tempat wisata, transportasi lokal dan lain sebagainya (Matercard \& HalalTrip, 2017).

Ada pula beberapa hal yang mampu memengaruhi keputusan dari generasi muslim milenial dalam menentukan wisata, yaitu: (1) biaya penerbangan dan penginapan, (2) masalah keamanan dan terorisme, (3) ketersediaan makanan halal, (4) pengalaman baru dan menarik, (5) ketersediaan atraksi wisata, (6) keramahan orang lokal, (7) sentiment islamophobia, (8) cuaca, (9) fasilitas ramah muslim, (9) hiburan dan perbelanjaan serta (10) durasi penerbangan (Mastercard \& Halaltrip, 2017).

\section{Hasil dan Pembahasan}

Era pariwisata 4.0 terjadi karena adanya pengaruh transformasi digital di sektor pariwisata. Era ini telah memberikan perubahan signifikan pada industri pariwisata terutama pada generasi milenial. Sejak terjadinya pergeseran budaya siber, generasi milenial secara besar memanfaatkan platform digital dalam mengakses sejumlah informasi terkait pariwisata. Hal tersebut memiliki keterkaitan terhadap berubahnya ketertarikan wisatawan milenial akan sebuah destinasi dari sisi visualnya. Kini, milenial lebih tertarik mengunjungi destinasi wisata karena ingin mengabadikan 
Website: $\underline{\text { https://ojs.unikom.ac.id/index.php/common }}$

DOI Jurnal: https://doi.org/10.34010/common

DOI Artikel: https://doi.org/10.34010/common.v3i2.2601

segala momen. Hal tersebut pada akhirnya menjadi sebuah siklus, dimana pergeseran budaya siber memiliki keterkaitan dengan bagaimana secara visual milenial tergerak untuk berwisata.

Tipikal wisatawan milenial ini, selain menjadikan milenial memiliki waktu yang ekstra untuk berada di sebuah destinasi wisata, juga menjadikan generasi ini memiliki karakteristik unik, alasan ini yang menjadikan sektor pariwisata Indonesia harus mampu beradaptasi untuk menyesuaikan perubahan pasar pariwisata jika ingin menjangkau peluang milenial sebagai the future tourist, tiga tipe tersebut adalah sebagai berikut:

a) Milenial cenderung mengalokasikan pengeluaran mereka secara langsung pada komunitas lokal;

b) Milenial akan tetap berwisata meskipun kondisi keuangan negara sedang tidak baik;

c) Memiliki kecenderungan untuk mengajak orang lain mengunjungi sebuah destinasi (Hakim, 2018).

Dapat dijelaskan bahwa kepribadian wisatawan, dapat memberikan dampak pada persepsi wisata. Persepsi wisatawan adalah persepsi luas terhadap atraksi, lingkungan, produk dan jasa di destinasi pariwisata, berbagai jenis wisata berbeda mempunyai persepsi berbeda (Robbins \& Coulter, 2012; Hilery, et al 2001). Karakteristik wisatawan generasi milenial dapat dilihat sesuai karekteristik remaja adalah sebagai berikut:

a) Diversely motivated artinya giat, berpetualang, mampu membangun budaya, dapat beraktivitas baik sendiri maupun berkelompok;

b) Socio-economically introverted, artinya mereka senang mengerjkan aktivitas yang mandiri dan tidak segan membelanjakan uang pada produk /jasa sesuai kesenangan; c) Socially driven, artinya memiliki disposable income tinggi, peduli atas merek, umumnya membelanjakan uang demi kebutuhan personal, busana yang memberikan mereka status;

d) Sports Oriented, senang kegiatan mengandung olahraga, fasilitas home video.

Terlepas dari fenomena atau kebiasaan generasi milenial saat ini yaitu melakukan kunjungan ke suatu destinasi hanya ingin berbagi momen di sosial media melalui foto ataupun video sebagai ajang eksistensi diri, selain itu generasi milenial juga masih mempertimbangkan faktor citra merek destinasi itu sendiri dalam menentukan suatu kunjungan. Citra merek destinasi yang positif dan sesuai harapan pengunjung akan menimbulkan kepuasan kunjungan. Kepuasan pengunjung generasi milenial nyatanya tidak hanya timbul dari hasil foto atau video yang berhasil diambil di destinasi yang mereka kunjungi untuk kepentingan media sosial masing-masing melainkan juga timbul dari adanya citra merek destinasi yang positif. Kepuasan dapat timbul melalui perbandingan antara harapan pengunjung generasi milenial sebelum berkunjung dengan pengalaman yang mereka rasakan melalui keputusan berkunjung yang disepakati. Pengalaman yang dihasilkan dari keputusan berkunjung akan mengarahkan minat pengunjung generasi milenial untuk melakukan kunjungan ulang pada destinasi yang sama diwaktu yang akan datang. Tidak berbeda dengan generasi muslim milenial.

Lahirnya sebuah fenomena baru tingkat global yaitu destinasi wisata halal menjadi bagian dari perkembangan pariwisata di berbagai belahan negara di dunia. Hadir sebagai alternatif dalam memilih destinasi, yang selama ini dianggap bebas dari prinsip-prinsip syariah yang sejatinya menjadi kewajiban bagi 
Website: $\underline{\text { https://ojs.unikom.ac.id/index.php/common }}$

DOI Jurnal: https://doi.org/10.34010/common

DOI Artikel: https://doi.org/10.34010/common.v3i2.2601

setiap muslim. Destinasi wisata halal saat ini dan bahkan jauh ke depan, akan menjadi branding baru di dunia pariwisata, terutama oleh wisatawan muslim.

Pada dasarnya konsep dari halal lifestyle sederhana, karena suatu yang halal sudah pasti baik, bersih, dan sehat tentunya. Bila kita mengkonsumsi yang halal maka akan mendapat sebuah kebaikan dan terhindar dari keburukan. Oleh sebab itu, negara-negara yang bukan mayoritas berpenduduk muslim juga ikut berpartisipasi. Maka tidak heran bahwa negara non-muslim juga ikut berpartisipasi dalam halal lifestyle ini. Saat ini telah banyak sektor yang mendukung penerapkan gaya hidup halal. Halal lifestyle dapat memenuhi kebutuhan sehari-hari masyarakat, baik dalam dunia jasa keuangan, wisata, obat-obatan yang berbahan dasar halal, makanan-minuman, pakaian sehari-hari, komestik bagi penampilan, serta pola hidup lainnya yang berbasis prinsip syariah yakni halal.

Indonesia memiliki strategi yang baik dalam wisata halal. Orientasi yang dibangun ialah pengembangan atraksi pariwisata untuk meningkatkan daya saing melalui kepedulian terhadap lingkungan, komunitas, komunitas, pemerintah, pelaku bisnis terkait pariwisata dan semua pihak terkait untuk bersama-sama menciptakan citra yang baik (Agustina \& Afriadi, 2019). Islam di Indonesia memiliki kesan yang baik dan dikenal secara internasional dengan Islam yang damai. Kesan ini harus menjadi pintu gerbang menuju pariwisata halal di Indonesia untuk mengembangkan pariwisata halal yang berorientasi ekosistem. Meskipun Indonesia tidak menempati peringkat pertama dalam kunjungan wisata halal, ini dapat menjadi potensi besar bagi Indonesia karena memiliki banyak tempat wisata yang dapat menjadi kunjungan ke komunitas dunia.
Sinergi antara program yang dikelola oleh Kementerian Pariwisata serta prediksi jumlah perjalanan wisata yang dilakukan wisatawan generasi muslim milenial bertujuan agar generasi milenial mampu menjadi garda terdepan dari industri pariwisata dapat berperan penting sebagai batu loncatan dari industri pariwisata halal yang banyak berkembang melalui halal lifestyle agar mampu berkembang dan lebih dipahami oleh masyarakat secara luas melalui media digital yang telah banyak dikuasai oleh generasi milenial.

Lahirnya generasi muslim milenial dari hasil era digitalisasi dan informasi menjadi peluang dalam memanfaatkan mereka sebagai pelopor wisata halal menjadi lebih mudah dengan mengembangkan kemampuan inovatif, aktif berkolaborasi, hypertechnology serta tidak lupa agar tetap mengedepankan prinsip-prinsip syariah dalam prosesnya.

\section{Kesimpulan dan Rekomendasi}

Wisata halal telah menjadi studi yang mulai berkembang beberapa tahun terakhir. Dengan segala upaya dan peluang yang telah dikembangluaskan oleh industri pariwisata mampu memberikan kemudahan dalam memetakan, mengembangkan dan memberikan arahan untuk memahami konsep dari wisata halal.

Adanya peningkatan jumlah wisatawan muslim merupakan peluang bagi sektor pariwisata dalam mengembangkan wisata halal. Saat ini banyak negara dengan mayoritas maupun minoritas muslim berupaya mengembangkan wisata halal. Manfaat pengembangan wisata halal menjadi penting karena dirasakan secara menyeluruh oleh wisatawan muslim maupun non-muslim.

Era pariwisata 4.0 merupakan pengaruh perubahan digital dalam industri pariwisata, perubahan ini memberikan 
Website: https://ojs.unikom.ac.id/index.php/common DOI Jurnal: https://doi.org/10.34010/common

DOI Artikel: https://doi.org/10.34010/common.v3i2.2601

pengaruh yang cukup menyeluruh terutama pada generasi milenial. Untuk ini generasi milenial, terutama muslim milenial harus mampu memanfaatkan era pariwisata 4.0 sebagai sumber kompetitif untuk mengedepankan pariwisata Indonesia di mata dunia. Hasil dari transformasi pariwisata 4.0 dapat ditempuh dengan cara digitalisasi yang kini banyak dimanfaatkan oleh generasi milenial.

\section{Daftar Pustaka}

Abdul Rahman, R., Rezai, G., Mohamed, Z., Shamsudin, M. N., \& Sharifuddin, J. 2013. Malaysia as Global Halal Hub: OIC Food Manufacturers' Perspective. Journal of International Food \& Agribusiness Marketing, 25 (sup1), 154-166.

Agustina, A. H., Afriadi, R. D., Pratama, C., \& Lestari, A. 2019. Platform Halal Lifestyle dengan Aplikasi Konsep One Stop Solution. Falah: Jurnal Ekonomi Syariah, 4(1), 56-68.

Albinger, J. 2009. Economic Model for Monopoly Analysis in Telecommunication: Proposal to Demonstrate Uniqueness.

Al-Hamarneh, A., \& Steiner, C. 2004. Islamic Tourism: Rethinking the Strategies of Tourism Development in the Arab World After September 11, 2001. Comparative Studies of South Asia, Africa and the Middle East, 24 (1), 173-182.

Battour, M. 2018. Muslim Travel Behavior in Halal Tourism. Mobilities, Tour. Travel Behaviour Context. Boundaries.

Battour, M., \& Ismail, M. N. 2016. Halal Tourism: Concepts, Practices, Challenges and Future. Tourism
Management Perspectives, 19, 150154.

Battour, M., Ismail, M. N., \& Battor, M. 2011. The Impact of Destination Attributes on Muslim Tourist's Choice. International Journal of Tourism Research, 13 (6), 527-540.

El-Gohary, H. 2016. Halal Tourism, is it Really Halal?. Tourism Management Perspectives, 19, 124-130.

Fitriani, D. R., Wulandari, C., \& Ohorella, N. R. (2019, April). The Power of "Instagrammable" In Destination Branding: Jakarta Millenial Tourist Case Study. In Conference On Communication and News Media Studies (Vol. 1, pp. 328-328).

Hakim, I. N. "Pergeseran Budaya Siber \& Visual di Sektor Pariwisata Indonesia" Respon Kementerian Pariwisata Menghadapi era Tourism 4.0 Melalui Peran Komunitas Milenial \& Pengembangan Destinasi Digital. In Seminar Nasional Seni dan Desain 2018 (pp. 275-282). State University of Surabaya.

Han, H., Al-Ansi, A., Olya, H. G., \& Kim, W. 2019. Exploring Halal-Friendly Destination Attributes in South Korea: Perceptions and Behaviors of Muslim Travelers Toward a non-Muslim Destination. Tourism Management, 71, 151-164.

Henderson, J. C. 2010. Sharia-Compliant Hotels. Tourism and Hospitality Research, 10 (3), 246-254.

Jaelani, A. 2017. Halal Tourism Industry in Indonesia: Potential and Prospects. International Review of Management and Marketing, 7 (3), 25-34. 
Website: https://ojs.unikom.ac.id/index.php/common DOI Jurnal: https://doi.org/10.34010/common

DOI Artikel: https://doi.org/10.34010/common.v3i2.2601

Jafari, J., \& Scott, N. 2014. Muslim World and its Tourisms. Annals of Tourism Research, 44, 1-19.

Kementerian Pariwisata. 2015. Laporan Akhir Kajian Pengembangan Wisata Syariah. Kementerian Pariwisata: Jakarta.

Kim, S., Im, H. H., \& King, B. E. 2015. Muslim Travelers in Asia: The Destination Preferences and Brand Perceptions of Malaysian Tourists. Journal of Vacation Marketing, 21 (1), 3-21.

Mastercard and Crescent Rating. 2016. Global Muslim Travel Index 2016. Dalam http://crescentrating.com/reports/mast ercard-crescentrating-global-muslimtravel-index-gmti-2016.html. Diakses bulan Juli 2019.

Meilani, Y. C. P. 2016. Identifikasi Aspek Sumber Daya Manusia Pariwisata Subsektor Perhotelan di Tangerang Berdasarkan Persepsi Wisatawan Generasi Milenial. Conference on Management and Behavioral Studies Universitas Tarumanagara.

Mohsin, A., Ramli, N., \& Alkhulayfi, B. A. 2016. Halal Tourism: Emerging Opportunities. Tourism Management Perspectives, 19, 137-143.

Nugraheni, A. I. P., Nugraha, B. S., Yuda, N. P., \& Pancawati, N. 2019. Persepsi Generasi Milenial Indonesia Terhadap Pariwisata Yang Berkelanjutan. Jurnal Kepariwisataan, 13 (1), 69-82.

Pew Research Center. 2017. The Changing Global Religious Landscape. Dalam http://www.pewforum.org/2017/04/05/ the-changing-global-religiouslandscape/. Diakses bulan Juli 2019.
Razalli, M. R., Abdullah, S., \& Hassan, M. G. 2012. Developing a Model for Islamic Hotels: Evaluating Opportunities and Challenges.

Samori, Z., Salleh, N. Z. M., \& Khalid, M. M. 2016. Current Trends on Halal Tourism: Cases on Selected Asian Countries. Tourism Management Perspectives, 19, 131-136.

Satriana, E. D., \& Faridah, H. D. 2018. Halal Tourism: Development, Chance and Challenge. Journal of Halal Product and Research, 1 (2), 32-43.

Subarkah, A. R. 2018. Diplomasi Pariwisata Halal Nusa Tenggara Barat. Intermestic: Journal of International Studies, 2 (2), 188-203.

Subarkah, A. R. 2018. Potensi dan Prospek Wisata Halal Dalam Meningkatkan Ekonomi Daerah (Studi Kasus: Nusa Tenggara Barat). Jurnal Sosial Politik, 4 (2), 49-72.

Susilawati, I. (2019, March). Peran Generasi Milenia Muslim Dalam Pengembangan Ekonomi Kreatif Berbasis Kearifan Lokal. In Proceeding: International Conference on Islamic Studies (ICIS) IAIN Ponorogo (pp. 189-202).

Utama, I. G. B. R., \& Mahadewi, N. M. E. 2018. Metodologi Penelitian Pariwisata dan Perhotelan.

Widagdyo, Kurniawan Gilang. 2015. Analisis Pasar Pariwisata Halal Indonesia. Tauhidinomics, 1 (1), 7380 .

Widhasti, G. B., Damayanti, C., \& Sardjono, H. S. 2018. Diplomasi Publik Pemerintah Republik Indonesia melalui Pariwisata Halal. Jurnal Solidaritas: Jurnal Ilmu-ilmu Sosial, 1 
Jurnal Common | Volume 3 Nomor 2 | Desember 2019

Website: https://ojs.unikom.ac.id/index.php/common DOI Jurnal: https://doi.org/10.34010/common

DOI Artikel: https://doi.org/10.34010/common.v3i2.2601

(1).

Zaei, M. E., \& Zaei, M. E. 2013. The Impacts of Tourism Industry on Host nd Research, 1 (2), 12-21.
Community. European Journal of

Tourism Hospitality 